\title{
Language ideologies and the politics of language in post- colonial Africa
}

\author{
H. Ekkehard Wolff \\ Emeritus Professor, Leipzig University, Germany \\ E-mail: ekkehard.wolff@gmx.de
}

\begin{abstract}
Africa is highly ideologised in terms of two antagonistic positions. Facing two extreme ideological positions, namely what one might call '19th century European nation state-ideology' vs '20th/21st century African Renaissance-ideology', language planners and decision-makers in Africa are caught in a complex dilemma. The paper begins by sketching out salient differences between the two positions: (1) Ideologies based on European historical-cultural experience, which gave rise to a particular 'Western' mind-set; this mind-set is built on convictions regarding European exceptionalism and on notions linked to linguistically and culturally homogenous nations. (2) Ideologies informed by anticolonialist struggle and anti-imperialist philosophy which, further, rest on the recognition of sociolinguistic realities in Africa that are different from 'the West', i.e. being characterised by extreme ethnolinguistic plurality and diversity. While the first position continues to have considerable impact on academic and political discourse in terms of prevailing Eurocentric perspective and attitudes infested by Orientalism, the second is rooted in idealistic romanticism relating to notions of Universal Human Linguistic Rights and of African Identity and Personality. Political strategies embedded in any of these apparently mutually exclusive ideological positions have been and still are widely discussed in academic and political circles across Africa. A third position and the one adhered to in this presentation, is that of bridging this ideological divide by advocating multilingual policies for Africa, which would combine indigenous languages of local and regional relevance with imported languages of global reach towards the strategic goal of mother tongue-based multilingualism (MTBML). Interestingly, the ongoing highly controversial debate in Africa tends to overlook the fact that MTBML is exactly the 'language(s)-ineducation policy' that most so-called developed countries, including the former colonial powers of Europe, have long since installed to best serve their own political interests and economic progress. Therefore, it remains somewhat paradoxical that African postcolonial governments copy from European models those features that are incompatible with sociolinguistic facts on the ground, like monolingual policies in the face of extensive multilingualism, but do not copy features that would be beneficial in Africa as well, like operating professional foreign language teaching and learning through a familiar medium of instruction.
\end{abstract}

Key words: Applied African Sociolinguistics, language ideologies, language policies and politics, linguistic and cultural imperialism, multilingualism and polyglossia

\section{Introduction}

Academic and political discourse on language policies and language use in post-colonial Africa tends to be highly ideologised and appears to be caught between a rock and a hard place, so to 
speak. ${ }^{1}$ The ongoing debate suffers from a mismatch between the multilingual realities in the African post-colonies and the prevailing political ideology that governs mainstream discourse on nation-building inside and outside Africa. Current mainstream discourse on 'development' and 'nation-building' is based on ideological positions which advocate official monolingualism. For most African countries that are essentially pluralistic in terms of languages, cultures, and ethnic composition, such official monolingualism would imply to opt for some kind of 'neutral' or 'unifying' language. The idea is that such heterogeneous polities should eventually conform to European models of a 'nation state', which are characterised by factual or ideologically postulated linguistic, cultural and possibly ethnic homogeneity, ideally allowing one to speak of one single 'nation' populating their own 'nation state' (hence we speak of 'titular nations' for such states). Political discourse tends to be monopolised by 'Western' social sciences, which reflect hegemonic ideologies based on linguistic and cultural imperialism, and which historically align with the European 'Project Nation' (Ehlich 2009, and cf. below). Not the least under the ideological impact of both Eurocentrism and Orientalism (Said 1978), the current Western mind-set would view the European standard languages of the former colonial powers as being 'essentially superior' to the 'essentially inferior' indigenous vernaculars, often belittled as 'dialects', outside the Western world. Consequently, in this line of thinking, all 'modernisation' and 'development', in particular (higher) education, can only and must be conducted in these 'superior' languages in order to meet the models provided by 'Western civilisation'. The European 'Project Nation' is considered extremely successful and has been turned into a prototype of modern statehood. Since it is understood as being largely based on the hegemonic imposition of one 'superior' language over lesser vernaculars or 'dialects', governments in most African post-colonies have been tempted and advised to copy such models with regard to their own national language policies. However, the ideology underlying the import of such policies is basically Social Darwinist by a priori accepting essential 'evolutionary' differences to exist between human societies, with some being more 'advanced' than others, and thus legitimises colonialism. In terms of language policy, this position favours exoglossic monolingualism, i.e. the imposition of one foreign 'neutral' or 'unifying' language. It disregards the historically grown sociocultural realities in Africa with roots in the continent's characteristic territorial multilingualism. Such policies foster language attitudes that target the eradication of multilingualism for all official purposes, including formal education, in the emerging post-colonial 'nation states'. In short, the ideological presupposition is that modern statehood in Africa must be 'de-Africanised' in order to match Western models. This widely shared position has been and remains under criticism for its inherent racism and continued linguistic and cultural imperialism. ${ }^{2}$

More recently, counteractive ideological debate aims to re-establish major African languages in domains of high prestige and power, such as in higher education, particularly in the South

\footnotetext{
${ }^{1}$ On previous occasions, I have referred to this as navigating language policies in Africa between Scylla and Charybdis, cf. Wolff (2014b) and section 3 below.

${ }^{2}$ European historical experience would have been able to provide an alternative model, namely that of a multinational state, like the Habsburg monarchy, the Soviet Union, and later Yugoslavia, for instance. These models, however and in retrospective, did obviously not succeed in recent European history, and none of the leading nations of these multinational states had become involved in colonial activities in Africa. Thus, the multinational model has never been tested for post-colonial statehood in Africa - apart from somewhat akin political sloganeering and paying lip-service to notions such as 'Rainbow Nation' and 'Unity in Diversity'. For a detailed discussion of perceptive and ideological distortions in Western perspectives on Africa, and their continued detrimental impact for sustainable modernisation and development, the reader is referred to the author's most recent book (Wolff 2016a), which also contains a list of relevant sources and a glossary of technical terms.
} 
African context (cf. Kaschula 2013, Hibbert and Van der Walt 2014). For instance, both postrevolutionary Ethiopia and post-apartheid South Africa are experimenting with 'empowerment' and 'intellectualisation' of their major regional languages (cf. Wolff 2013a, Kaschula 2013), in the case of Ethiopia up to the point of involving decentralisation of power under federal constitutional provisions, i.e. allowing the individual states within the federation to decide on their own (local) 'working language' of government and non-higher education. Much hope for empowerment of indigenous local and regional languages is linked to the effects of Kenya's 2010 Constitution and the subsequent creation of 47 counties in the place of the former eight provinces (cf., for instance, Ogone 2013). It would be along such lines of innovative political ideology, i.e. by recognising the multilingual and multi-ethnic profiles of African polities, that policies and politics could be remarried with sociolinguistic reality in post-colonial Africa.

This paper is written in the framework of 'Applied African Sociolinguistics' (cf. Wolff 2016a, 2016b), which is emerging as a new sub-discipline based on the 'language as resource' paradigm (cf. Ruíz 1984). It argues in favour of and illustrates, an interdisciplinary macrosociolinguistic approach to discourse on nation-building and comprehensive language planning for multilingual, multicultural and multi-ethnic societies in Africa. This approach is deeply rooted in German-speaking traditions of African linguistics (Afrikanistik), which was conceived and developed as an autonomous academic discipline, parallel to Oriental Studies, in institutions of higher learning in Berlin, Leipzig, Hamburg, and Vienna since the turn of the 20th century at the peak of Imperial Germany's short-lived past as a colonial power before 1919 (cf. Wolff 2013b, 2014a, 2016a for more details).

\section{European experience versus African reality}

Using the term 'post-colonies' for the newly independent states in Africa recognises the continued existence of overt and covert dependencies from the former 'colonial master'. Such dependencies may be of a bilateral nature or through global agencies of perpetual post-colonial linguistic and cultural imperialism, such as the Commonwealth of Nations, the Organisation Internationale de la Francophonie, the Comunidade dos Países de Língua Portuguesa, and even the Nederlandse Taalunie, among others. Apart from economic, financial, political and military dependencies, there is, generally speaking, a strong ideological impact to be observed in 'development communication' between the North and the global South. This impact is eagerly embraced, consciously or subconsciously, by members of the post-colonial elite in the newly independent states, particularly so in Africa. This ideological impact will be discussed in more detail in section 3 below. In the present section, we will look at the historico-cultural background of the particular European (or, more generally speaking, Western) perception of their own languages and civilisations as being 'superior' to those of other world regions, and in particular with regard to sub-Saharan Africa, where languages and cultures are considered to be 'inferior' in many ways and for many reasons. This European mind-set is based on the belief in European exceptionalism at whose bottom lie racism and a Social Darwinist ideology that need to be brought to light in order to understand present Western perspectives on multilingualism and language policy in the African context. These often subconscious attitudes influence current linguistic and political ideologies which, to no little extent, are shared by many members of the African post-colonial elite, and further by all kinds of stakeholders in mainstream discourse on development and, in particular, on formal (and including higher) education. 
First of all, the fundamental sociolinguistic differences between the situations in Modern Age Europe and in colonial as much as in post-colonial Africa need to be pointed out. Mainly in the societies of the former colonial powers (Belgium, France, Germany, Italy, Netherlands, Portugal, Spain, and the United Kingdom), certain linguistic facts and cultural experiences prevailed which, until quite recently, shaped Western thought and attitude. It is through these Eurocentric lenses (cf. section 3) that 'the West' tends to look at the situation in Africa.

What will follow here for better understanding of the differences, is a short outline that will contrast some of the sociolinguistic and sociocultural basics in Europe with those found in Africa. It will show and explain salient differences of country profiles with regard to languages in terms of their numbers, distribution and degree of diversity, and number of speakers. Based on the differences, there can, therefore, be no surprise that Europeans, in particular during the period of active colonialism, felt the urge and legitimisation to become agents of occidental Christian and civilising missions among 'pagan' and even Muslim populations outside Europe. The idea was to bring the light of both Christian Revelation and European Enlightenment to Africa with the aim of moulding the societies and cultures of the 'primitive tribes of Africa' into copies of the 'civilised nations of Europe'. Quite naturally, the Europeans started off from their own self-assured ideological position, which is based on the internalisation of European exceptionalism (cf. section 3); it assumes both racial and cultural cum religious supremacy as given. Accordingly, they would turn the sociolinguistic and sociocultural situation back home into a model for export; this would be part of their self-declared civilising mission among the 'pagan tribes of savage natives' in Africa.

European public awareness outside expert circles, despite all historical experience of active colonialism, tends to maintain a low horizon that hardly ever reaches beyond the confines of the continent; Europeans consider their own continent to be rich in terms of linguistic and cultural plurality and diversity. Fact is that Europe counts 45 states between the Atlantic coast and the Ural, being home to almost 90 nations. In European perspective and based on the idealistic notion of a homogeneous nation and nation state, it is considered odd and potentially problematic that not every such 'nation' should have its own 'nation state'. On top of it, about 300 so-called national minorities enter the picture; this makes most European nation states rather heterogeneous - despite counterfactual celebrations of sociocultural homogeneity, which is often used for nationalist propaganda. Some of the so-called minorities in Europe count more members than the inhabitants of some of its nation states, others count only a few thousand, altogether they amount to almost 100 million people. Somewhat counter to the notion of homogeneous nations, and despite all globalising and standardising efforts, Europeans tend to consider diversity and colourfulness a trademark of European culture. ${ }^{3}$ However, compared with the ethnolinguistic and cultural plurality and diversity in Africa, this self-image that Europeans have regarding their continent does not stand the test of time and would appear to suffer from both under-information about the degree of Africa's essential ethnolinguistic and cultural plurality and diversity, and of over-estimation of the complexity of the European situation. Possibly, this over-estimating self-deception regarding European linguistic and cultural plurality and diversity accounts for the emergence of a Eurocentric attitude according to which any situation that would quantitatively surpass the European one must be considered chaotic and unmanageable - such as would appear to be the case in Africa.

\footnotetext{
${ }^{3}$ Freely quoted from the invitation pamphlet for the 9th International Ferdinand Tönnies Symposium, November 13-14, 2015, whose general theme was 'National Minorities in Europe'. Section 2 of the present paper rests partly on my presentation at that symposium (Wolff 2015).
} 
In comparison with Europe, Africa's linguistic and cultural plurality and diversity is much higher. On the other hand, with up to 55 states on the African continent and including some islands, their number is not much higher than that of Europe. While it is hardly possible to give exact numbers for different 'peoples' (in the sense of 'tribes', 'ethic groups', 'nations', Völker, etc.) in Africa, more reliable even if at times controversial figures are available for counting languages. In its 2015 edition, the Ethnologue (Lewis et al. 2015) gives 2138 languages for Africa. This would mean that, on average, there would be about 40 languages per state. It would also mean that, again quite different from the European situation, more than $99 \%$ of all African ethnolinguistic groups do not have their own 'nation state'. Here it becomes immediately obvious that the European notion of nation state would appear to make little if any sense in the African context. About 50 indigenous African languages are so-called cross-border languages and cover territories of between two and twenty neighbouring independent states. These 'interAfrican languages' usually count among the big languages of Africa, together with some imported non-indigenous languages on the continent. Obviously, and even in the light of extended periods of European colonialism, Christian mission and economic globalisation, Africa's ethnolinguistic and cultural plurality and diversity surpasses that of Europe by far. A closer look reveals the following picture; figures are based on the Ethnologue (Lewis et al. 2015). Table 1 indicates numbers of different languages per country in Europe and in Africa. The clearly emerging pattern shows that in terms of numbers of languages, general and per country, Africa outnumbers Europe by far.

Table 1: Number of languages in Europe and Africa

\begin{tabular}{|c|c|c|c|c|}
\hline \multicolumn{2}{|c|}{ Europe } & Number of languages: & \multicolumn{2}{c|}{ Africa } \\
\cline { 4 - 5 } \cline { 5 - 5 } Countries & Languages & Ranges & Countries & Languages \\
\hline 40 & $2-17$ & less than 20 & 23 & $2-18$ \\
\hline 4 & $23-27$ & between 20 and 50 & 16 & $21-45$ \\
\hline- & & between 50 and 100 & 5 & $54-82$ \\
\hline 1 & 105 & more than100 & $125-520$ \\
\hline
\end{tabular}

Europe is home to only one linguistic giant with 105 different languages, namely the Russian Federation. This is explained by the fact that the Russian Federation, like the former Soviet Union, also covers large parts of the Asian continent as a result of Russian imperialism from the 18th century onward. Post-colonial Africa presently hosts five linguistic giants: Nigeria (520), Cameroon (280), The Democratic Republic of the Congo (210), Chad (131), and Tanzania (125). ${ }^{4}$

Another difference pertains to language vitality. While in the terminology of the Ethnologue (Lewis et al. 2015) 101 of the 286 languages in Europe are considered 'in trouble' or even 'dying', i.e. $35 \%$, the figures for Africa are only $17.6 \%$ (i.e. a total of 376 languages). This confirms a general observation according to which the vast majority of the indigenous African languages can be described, again in the terminology of the Ethnologue, as 'vigorous', 'developing' or even 'institutional'. This supports the view that Africans tend to maintain a high degree of language loyalty to both their mother tongues and other African languages which make up their individual linguistic repertoires, in addition to using ex-colonial languages of European provenance.

\footnotetext{
${ }^{4}$ Before South Sudan seceded into independence in 2011, Sudan also counted among these giants with more than 130 languages.
} 
The much higher number of languages in Africa, as compared to, for instance, Europe reflects a global phenomenon, which has long been referred to as 'latitudinal diversity gradient' (LDG) in biology. LDG means that we expect a higher number of species, as we do with languages and genetic units of languages, in lower latitudes, i.e. closer to the equator, and fewer numbers in higher latitudes. With Africa being located in the global region of the lower latitudes on both sides of the equator, and Europe located quite remote from it in much higher latitudes, LDG already predicts much higher language diversity in Africa as compared to Europe. Turning this global fact into ideology, Europeans, therefore, accept fairly low numbers of languages and relatively little language diversity as something 'normal', and in this same perspective they consider the situation in Africa quasi 'abnormal'. In a second step, Europeans will then equate their own notion of 'normal' with 'developed', and equate their notion of 'abnormal' with 'underdeveloped'.

There are also considerable differences in terms of genealogical diversity of languages. Europe provides a fairly homogeneous picture. ${ }^{5}$ In total, $95 \%$ of its languages belong to only one major genetic unit, namely the Indo-European (IE) language phylum. Furthermore, only three language families within IE account for the vast majority of the languages, i.e. the Slavic, Romance, and Germanic languages. Smaller language groupings within IE are Greek, Albanian, Irish, Baltic, and Romani. In addition to IE languages, we find only 2.71\% Uralic languages, $2.06 \%$ Altaic languages, less than 1\% Semitic (Maltese), plus the isolated unit of Basque.

The African situation is quite different. With 70\%, the about 1500 languages of the NigerCongo phylum form the biggest linguistic unit in Africa; in terms of number of individual languages, this phylum may well be also the largest language phylum on our planet. With about 350 languages, the Afroasiatic language phylum accounts for $16.4 \%$. The about 200 Nilosaharan languages account for $9.4 \%$. The remaining possibly less than 22 living Khoisan languages make up for only $1 \%$ of the African languages. Clearly, genetic diversity is much higher among the African languages than among the European languages most of which belong to just one linguistic phylum, namely Indo-European.

However, the major sociolinguistic difference between Europe and Africa pertains to language 'muscle' in terms of numbers of speakers, counting mother tongue and second or third language speakers. Indigenous African languages are spoken by any number of speakers between a few hundred (or even less) and 100 million (as in the case of Kiswahili and, possibly, Hausa). ${ }^{6}$ The situation in Africa (with more than 2000 languages) matches the global situation (with between 6000 and 7000 languages) insofar as only 4\% of the languages are spoken by more than one million speakers. In Africa, this would apply to between 80 and 90 languages. Globally, two thirds (65\%) could be referred to as 'smaller languages', and 31\% have only a few hundred speakers, or less. Available figures for Africa show that, in addition to the $4 \%$ of languages with more than 1 million speakers, only 20\% have between 100000 and 1 million speakers, while three quarters (75\%) have less than 100000 speakers, including the 50\% that probably have (quite often considerably) less than 50000 speakers.

\footnotetext{
${ }^{5}$ Figures in this paragraph are taken from Ehlich (2009).

${ }^{6}$ Numbers for mother tongue speakers would be found towards the lower end of such scales, figures would increase according to the numbers of second or third language speakers in the case of languages that function as regional, national or cross-border lingua francas.
} 
The situation in Europe is quite different, a fact which has prompted Ehlich (2009) to refer to Europe as 'oligoglottic' continent. Against the backdrop of the low percentage of 'big' languages with more than one million speakers, which in a world-wide perspective account for only about 4\% (i.e. between 240 and 280 languages), Ehlich points out that there are only 12 languages on our planet that have more than 100 million speakers. However, the striking fact is that among these 12 'giant languages', half of them are from Europe. This is the more surprising in view of the fact that while Europe as a continent accounts for only less than $5 \%$ of the languages of the world, it is nevertheless home to $50 \%$ of these giant languages. This fact accounts for the astonishing misconception that Europeans share when looking at 'language size' by numbers of speakers. The presence of languages in Europe with extremely large numbers of speakers prompts Europeans to consider 'a proper language' to have several million speakers, like it is the case with most of their official or national languages at home. It is part of their historically grown mind-set to consider smaller languages as negligible 'vernaculars' or even 'dialects' - the fact not withstanding that such smaller languages account for $96 \%$ of the languages on this planet. ${ }^{7}$

Finally, there are major differences in the history and resulting sociolinguistic profiles of the countries in question, i.e. European nation states on the one hand, and African post-colonies on the other. In 18th and 19th century Europe, all the languages forming a constitutive element of a nation state and including hegemonic languages of power, are meanwhile being considered as endoglossic. This would even apply to Hungarian and Maltese whose arrival in (Western) Europe dates to much older historical times and whose ultimate origins lie outside a narrower definition of Europe. In Africa, on the other hand, a number of major and powerful hegemonic languages are exoglossic by ultimate origin, in particular Malagasy, Arabic, and Afrikaans, plus the former colonial languages Dutch, English, French, German, Italian, Portuguese and Spanish. ${ }^{8}$ These exoglossic languages have an important role to play in the African linguistic landscape. In addition, there are a number of immigrant languages of mainly Asian provenance whose arrival usually dates back to the colonial period. Presently, but this is a situation which Africa shares with Europe, more recent waves of immigrants cross African and European borders, mainly refugees of (internal) wars in neighbouring countries, terrorism, climatic changes that lead to, or aggravate pre-existing, hunger and poverty. They all bring along additional languages and add to the ethnic, cultural and religious composition of national populations in both African and European countries.

Independent of and prior to the more recent immigrations, both European and African populations are made up of (ethno-) linguistic and cultural majorities and minorities who tend

\footnotetext{
${ }^{7}$ Citizens of the former colonial powers of Western Europe in particular, tend to overlook the fact that also in Europe as a whole there are a few nation states whose even titular nations are made up of speech communities with much smaller numbers of speakers, namely with less than 1 million members down to less than 100000 . Cases in point are, for instance, Romansh [35 000], Faroese [66 000], Irish [276 000], Icelandic [330 000], Luxemburgish [390 000], Montenegrin [510 000], Maltese [520 000], Estonian [1,1 million]. But again, it would appear that among Europeans who do not possess special expertise in linguistics, these languages and their relatively small numbers of speakers do not enter their image of their own continent; these languages hardly 'count' for them in the light of the hundreds of millions of speakers of English, Spanish, French, Russian, Portuguese and German, who shape the image of these European languages as more or less 'world languages' whose numerical muscle largely stems from colonialist expansion.

${ }^{8}$ Interestingly, there is a debate going on in certain intellectual circles in Africa whether, given their long historical presence in Africa, these languages should also not rather be considered 'African languages' by now, i.e. endoglossic of a secondary nature, so to speak.
} 
to be associated with different positions on sociocultural scales pertaining to status, prestige and power. It would appear to be a truism that endogenous majorities tend to sit high on such scales, while minorities, in particular exogenous immigrant minorities, are condemned to the lower ranks - a fact which links up with occasional outbursts of xenophobia and racist discrimination, if not genocide. In most parts of post-colonial Africa, however, the situation is reversed with regard to the former European colonisers and the small assimilated elite that they had left behind after independence. Regarding this post-colonial elite, like the colonisers before independence, it is a minority who has appropriated the exoglossic language of power, namely that of the former colonial master. They sit high on the polyglossia scale of language status and prestige, with even remarkably large endoglossic linguistic majorities now sitting low on that scale. ${ }^{9}$ This is referred to as the post-colonial class divide.

Another deep sociolinguistic divide is that between standard languages and non-standardised vernaculars and dialects. The European situation is characterised by the uncontested high status and prestige of standardised endoglossic (i.e. 'national') official languages that look back on a long history of many centuries of writing and literature. Indigenous African standard languages, on the other hand and where they exist, have a much shorter history and much smaller production of literature. They usually owe their standardisation to European missionaries at the turn of the 20th century. Present-day young urban speakers tend to consider them to be outdated and inacceptable means of communication and to still carry a smack of colonialism and European hegemonic dominance. There is a clear tendency to identify European standard languages with high status and prestige on the polyglossia scale, as opposed to indigenous languages, whether standardised or not, at the lower end of the polyglossia scale. This hiatus links to and supports the fact that the former are most often attributed the constitutional privilege of being installed as the 'official languages' in the African post-colonies, while indigenous languages are maximally awarded the lesser labels of 'national language' or 'coofficial national language' in the country's Constitution. On the higher levels of the scale there is little or no room for indigenous languages, pidgins and creole languages, or the rapidly developing urban lifestyle codes (also known as 'new urban vernaculars') like Sheng, Nouchi, Franlof, Camfranglais, Tsotsitaal, isiCamtho, Sepitori, etc. which mushroom in the African mega-cities and whose sociolinguistic nature and future deserve our attention.

To conclude: In terms of language attitudes and in order to explain the so-called European mind-set regarding multilingualism in the African post-colonies, what counts most are the criteria of 'language muscle' by number of speakers, standardisation history and tradition of literature production, and finally prestige and status as official language of a country. However, this often combines with racist and Social Darwinist positions, thereby creating language ideologies according to which certain languages are essentially 'superior' to others which, correspondingly, must be considered essentially 'inferior'. As a consequence, it has become current thinking that all official communication, formal education, sociocultural modernisation and economic development in the African post-colonies must be conducted through such 'superior' languages. These, of course, are the European standard languages, i.e. those of the former colonial masters. The 'inferior' indigenous African languages may then either be given some symbolic value as co-official and/or national languages in constitutional documents, or

\footnotetext{
${ }^{9}$ Such scales of status and prestige in terms of 'high' and 'low', when they differentiate between varieties of the same language, have long since been referred to as diglossia (Ferguson 1959). When different languages are involved, i.e. in multilingual contexts, I refer to this - in analogy to diglossia - as polyglossia. (See Fishman 1967, for instance, for a different terminology.)
} 
be used temporarily as assisting media of instruction in lower primary education within the framework of subtractive bilingualism; this means that usually they are phased out as medium of instruction after two or maximally three years ('early exit' models). It remains a remarkable aside that such low esteem of one's own indigenous languages appears to be very much a matter of African post-colonial societies; this does not appear to be the pattern in Asian post-colonies.

\section{The ideological impact of Eurocentrism, Orientalism, and the European 'Project Nation'}

In order to understand Western attitudes and ideological positions towards language matters we need to unearth the most salient features of (mainly West) European historico-cultural experience, which has contributed to the emergence of a particular intellectual mind-set (albeit with certain religious undercurrents rooted in occidental Christianity) that would appear to privilege Western Europeans to arrogantly look down on 'others', and not the least on Africans. I consider the following four interlocking modules to be most salient foundations of this European mind-set that has recently been referred to under the acronym WEIRD (WesternEuropean-Industrialised-Rich-Democratic): The belief in European Exceptionalism, the particular perspectives of Eurocentrism and Orientalism, and the experience of the European 'Project Nation'. These four pillars of what could be called the European mind-set will be shortly introduced in this section. They provide, often implicitly, much of the ideological background of ongoing academic, political and economic discourse on development and nation building in post-colonial Africa.

\subsection{European exceptionalism}

For the purpose of short introduction, I will quote from articles in Wikipedia (consulted 28 January 2016). First, we are told that:

[e]xceptionalism is the perception that a country, society, institution, movement, or time period is 'exceptional' (i.e., unusual or extraordinary) in some way and thus does not need to conform to normal rules or general principles. Although the idea appears to [have been] developed with respect to an era, today the term is particularly applied to national or regional exceptionalism.

The intellectual roots of the notion of exceptionalism are said to go back to national romantic philosophy in Europe, in particular to the German philosophers Johann Gottfried Herder (17441803) and Johann Gottlieb Fichte (1762-1814) and had strong influence on 19th century nationalism in Europe. European exceptionalism is dealt with in Wikipedia (consulted 28 January 2016) under the heading of The Great Divergence:

The Great Divergence, a term coined by Samuel Huntington (also known as the European miracle, a term coined by Eric Jones in 1981), referring to the process by which the Western world (i.e. Western Europe and the parts of the New World where its people became the dominant populations) overcame premodern growth constraints and emerged during the 19th century as the most powerful and wealthy world civilization of all time, eclipsing Qing China, Mughal India, Tokugawa Japan, and the Ottoman Empire. 
The process was accompanied and reinforced by the Age of Discovery and the subsequent rise of the colonial empires, the Age of Enlightenment, the Commercial Revolution, the Scientific Revolution and finally the Industrial Revolution. Scholars have proposed a wide variety of theories to explain why the Great Divergence happened, including lack of government intervention, geography, colonialism, and customary traditions.

Opinion leaders in the Western world, i.e. academics, public intellectuals and politicians, have settled cosily in their convictions about European exceptionalism and thus have developed and maintain a 'Eurocentric' perspective on the world around them.

\subsection{Eurocentrism}

Most Westerners have internalised the idea of European exceptionalism and allow it to merge with the universal phenomenon of ethnocentrism to breed what we call Eurocentrism. Ethnocentrism is the in-group centred judgement of out-group cultures and value systems, including linguistic and other meaningful behaviour. Ethnocentrism turns the in-group values into absolute criteria for judging others. The notorious 'Eurocentric mind-set' is created by extending this arguably natural feature of all human societies to a shared value system of Western and Central European Christian cultures and societies. Wikipedia (consulted 28 January 2016) offers the following definition:

Eurocentrism is a term coined in the 1980s, referring to the notion of European exceptionalism, a worldview centered on Western civilization, as it had developed during the height of the European colonial empires since the Early Modern period. Eurocentrism is the practice of viewing the world from a European perspective and with an implied belief, either consciously or subconsciously, in the preeminence of European culture. The term Eurocentrism itself dates to the late 1980s and became prevalent in the discourse during the 1990s, for instance in the context of decolonization.

\subsection{Orientalism}

The internalisation of European exceptionalism and the Eurocentric world view marry well with what Edward Said (1978) has referred to as 'Orientalism' in his still highly controversial book of the same title. Orientalism, again quoted from Wikipedia (consulted 28 January 2016), refers to:

...a patronizing Western attitude towards Middle Eastern, Asian and North African societies. In Said's analysis, the West essentializes these societies as static and undeveloped - thereby fabricating a view of Oriental culture that can be studied, depicted, and reproduced. Implicit in this fabrication, writes Said, is the idea that Western society is developed, rational, flexible, and superior.

Ultimately, this position relates back at least to the Age of Crusades mainly in the 12th and 13th century, the Reconquista with immediately subsequent beginning of European colonialism after 1492, and the era of the European Renaissance; it is echoed in present-day patterns of economic globalisation and post-colonial linguistic and cultural imperialism. This patronising attitude can be construed to include all 'exotic' aspects of African cultures and societies, as reflected in the 
topoi and their treatment in many literary and artistic productions particularly of the 19th and early 20th century in Europe.

Eurocentrism and Orientalism combined subscribe to the essentialist notion of superiority if not supremacy of the Western world, which has its foundations not the least in occidental Christian belief systems, and derive from it the legitimacy of its global hegemonic dominance. In philosophical and humanitarian terms, it almost demands to take up The White Man's Burden of the notorious poem by Rudyard Kipling of 1899 whose first verse encapsulates the message:

Take up the White Man's burden

Send forth the best ye breed

Go bind your sons to exile

To serve your captives' need;

To wait in heavy harness,

On fluttered folk and wild

Your new-caught, sullen peoples,

Half-devil and half-child.

\subsection{The European 'Project Nation'}

Modern European statehood ideology is closely connected to the notion of 'nation'. It postulates, as a sociocultural and ideological construct, the linguistic, cultural and/or ethnic homogeneity of an often titular nation. In present-day Europe's sociolinguistic reality, however, this is, nevertheless, barely the case. Even highly centralised nation states like France still live with considerable linguistic, ethnic and cultural heterogeneity despite centuries-long attempts towards unification and homogenisation. However, in Europe, and interestingly so from an African perspective, the development of modern nation states involved, in its early stages, the emergence of endoglossic lingua francas beyond Latin, which for centuries had been the hegemonic language of the church, scholarship, and legal documents; access to this language of power was channelled through elitist education for only small minorities, i.e. clergy and members of the aristocracy. The 'Printing Revolution' of Gutenberg's letterpress, not the least in combination with the impact of Luther's Protestant Reformation including translations of the Bible into the vernacular languages, stimulated the dynamic empowerment and intellectualisation of hitherto unwritten vernacular languages. They immediately became used for new and higher domains. With information now being distributed through fast and cheaply available printed materials in the language of the common people, the largely illiterate masses could be reached by publicly reading out such pamphlets. Eventually, one could speak of a democratisation of knowledge via increasing public access to printed information for the masses of hitherto illiterate peoples; this was achieved through the boosting of mother tongue literacy, which complemented the prevailing elitist literacy that was connected with Latin and restricted to the clergy and members of the aristocracy, most of the time. The modern European 'Project Nation' in the sense of popular sovereignty, i.e. non-feudalistic republican if not democratic rule, was massively boosted again by the French Revolution and the emergence of ideas concerning 'national languages', 'national literatures', 'national cultures', 'national identities', etc. The popular nationalist ideology in the emerging modern European nation states eventually fed into imperialist politics, which would result in the colonialisation of overseas territories. Nationalist global colonialism has led to establishing the European colonial empires whose overseas territories were subjected to hegemonic dominance in terms of the language and culture of the 'colonial master'. Irritatingly, at the point of gaining 
political independence from the former colonial powers of Europe around the year 1960, in most African post-colonies the sociolinguistic status quo ante was not changed. Apart from early anticolonialist activist discourse, 'mental decolonisation' was neither achieved nor even attempted, the hegemonic dominance of the ex-colonial language and culture, particularly in education and the production of literatures remained largely unchallenged (cf. Ngugi wa Thiong'o 1986).

\section{Between Scylla and Charybdis: Discourse on nation-building and language policies in Africa}

The imagery of Scylla and Charybdis known from Homer's epic poem Odyssey, which is considered a jewel of early European culture and literature, is based on a geographical fact, namely that of the well-known dangers for boats passing through the Strait of Messina between Sicily and the Italian mainland. In Greek mythology, Scylla and Charybdis were mythical sea monsters. Scylla was rationalised as a rock shoal on the Italian side of the strait, and Charybdis was a whirlpool off the coast of Sicily. Located close enough to each other, they were regarded as a sea hazard that posed an inescapable threat to passing ships and sailors; avoiding Charybdis meant passing too close to Scylla and vice versa. The legendary seafarer Odysseus in Homer's epic poem was, therefore, forced to choose which monster to confront while passing through the strait. He was advised and opted to pass by Scylla and lose a few members of his crew, rather than risk the loss of his entire ship and crew in the whirlpools of Charybdis.

In the case of African governments facing the need to design and implement adequate postcolonial language policies, African decision-makers face a similar dilemma. They are confronted (or are made to think so not the least by Western expatriate advisors) by a choice between two evils: Either to go for endoglossic policies but then likely to see their formally independent states drown in eternal underdevelopment, shipwrecked so to speak by the purportedly negative impact of received ethnolinguistic plurality and diversity (this is the Charybdis phobia), or to opt for exoglossic policies and risk to lose national identity and cultural authenticity by throwing all African mother tongue-languages overboard and jump for the life buoy of the next available global language of foreign origin - usually the language of the former colonial master (this is the Scylla phobia). As we will argue in section 5 below, on second sight this turns out to be a false dilemma, a fallacy.

\subsection{Charybdis: The fear of (complete) indigenisation in African language politics}

In Greek mythology, the Charybdis monster was believed to live under a rock on one side of a narrow channel. Three times a day, Charybdis swallowed a huge amount of water, before belching it back out again, creating large whirlpools capable of dragging a ship underwater. In African language politics, 'linguistic whirlpools' in the shape of up to hundreds of indigenous languages on their territories are feared to threaten 'development' and social cohesion of African independent states. In sociolinguistic terms, we would be speaking of territorial multilingualism. Firstly, we are dealing with manifestations of universal ethnolinguistic diversity as a reflection of the so-called latitudinal diversity gradient (cf. section 2). The second challenging feature is the quest for implementation of basically Utopian Universal Linguistic Human Rights, which would guarantee any person the right to use her/his preferred language for any purpose and, thereby, would foster the often implored development of 'African personality' and 'African identity (authenticity)'. However, politicians and many intellectuals fear the potential consequences of linguistically indigenising national communication and 
(higher) education. Deep down and infested by Eurocentric thinking, they anticipate two disasters: (1) the closing of the linguistic 'window to the world', which was only fairly recently opened for them during the period of colonialism by the access to the language of the European colonial power; and (2) that the official use of what they consider to be essentially inadequate indigenous languages will perpetuate underdevelopment and backwardness. This deep and double sociopsychological fear links up with political and economic fears of perpetuated disconnection also from world trade and affairs, i.e. that it would cement Africa's received marginalisation in global trade and commerce.

Those who are afraid of this option of full linguistic indigenisation remain convinced that, unless the hegemonic dominance of the ex-colonial languages as purportedly 'neutral/unifying' means for national communication is confirmed and even enhanced, any political attempt to establish national unity, efficient national communication, and an effective system of formal education will be futile. As a consequence, they fear, the state would drown in tribal particularism and, possibly, suffer secessionism. Therefore, those in fear of this 'political monster' urge that it must be killed. The way to kill it is the eradication and annihilation of all the various African languages and cultures on the national territory in order to sail the apparently smooth waters of nation-wide monolingualism by using English (or French, Portuguese, Spanish, or possibly Arabic) as the only language for all official business, including formal education. In the imagery of Ancient Greek mythology, and like the mythological hero Odysseus did, the captain of the state vessel will avoid Charybdis and rather sail close to the opposite coastline where, however, the Scylla monster will have to be faced!

\subsection{Scylla: The fear of external hegemonic dominance in African language politics}

In Greek mythology, the Scylla monster was believed to once have been a beautiful naiad, who was transformed into a monster with four eyes and six long necks equipped with grisly heads, each of which contained three rows of sharp teeth. Her body consisted of 12 tentacle-like legs and a cat's tail, while four to six dog-heads ringed her waist. In this form, she attacked the ships of passing sailors, seizing one of the crew with each of her heads and devouring them raw.

In African language politics and metaphorically speaking, the exclusive status of the languages of the former colonial masters may be equated with the grisly heads of the Scylla monster. As preeminent colonial legacy, the supremacy of the (mostly only and ex-colonial) official language in the post-colonies is feared to entail a drastic impoverishment of inherited types of multilingualism and multiculturalism in Africa. Further, official exoglossic monolingualism would cement elitism as marker of a postcolonial class divide since the linguistic 'window to the world' through English, French, Portuguese, even Afrikaans or Arabic is open only to the chosen few. Shifting, particularly of the elite, to a foreign and imposed language and culture would result, as some fear, in cultural and linguistic attrition resulting in the loss of African authenticity and identity. It would mean acceptance of eternal hegemonic language dominance through official exoglossic monolingualism (hence we speak of Anglophone, Francophone, Lusophone, Hispanophone, Nederlandophone, and Arabophone countries). As a political strategy, this would go with continued post-colonial imposition of an originally Eurocentric mind-set (the 19th century European 'Project Nation' as a further colonial legacy) and exoglossic monolingual imprisonment of African populations in terms of sociopsychological alienation from their ethnolinguistic roots and cultural identity. 
Like Scylla in Greek mythology being depicted as the better choice among the two evils, for many stakeholders in African language policies it would appear to be first choice to settle for a European-origin global language which would, on first sight, appear to be a highly attractive official communication tool. It would have to be acquired through formal education and would open the fervently desired 'window to the world'. In addition, it would appear to allow access to the assumed treasure-boxes of Western civilisations. However, the true nature of this 'political monster' becomes apparent on at least two levels of disaster: (1) It singles out only the chosen few who have privileged access to quality education through the foreign language. Such elitist system leaves uneducated 'masses' behind who remain struggling with a foreign medium in an underperforming educational system. Poor command of the foreign medium of instruction results in poor performance at examinations, in frequent class repetition, and in high dropout rates. In the end, such elitist system amounts to a post-colonial class divide and, in the end, to neo-apartheid where native speakers of the language of power are automatically privileged. (2) With those that are singled out as members of an elitist class based on foreign language competence, this linguistic alienation strategy, like the Scylla monster, devours the authentic African heritage encoded in the indigenous mother tongues, it turns potentially genuine African personalities into copycat caricatures of the foreign model, which is represented by the former colonial master's language and civilisation.

\subsection{Facing facts and countering myths concerning African language policies}

Unlike with the hero Odysseus in Homer's Ancient Greek epic poem, who was advised to face the 'either-or' decision and sail close to Scylla, losing some members of his crew, rather than opting for passing Charybdis and risk losing the ship and his whole crew, modern applied sociolinguistics is in a position to help African decision-makers to navigate the turbulent waters of language politics to reach a safe haven of adequate language policies. The solution is to simply avoid 'either-or' decisions and opt for 'as well as' strategies, i.e. doing one without necessarily leaving the other. This new approach has been referred to as mother tongue-based multilingualism strategy for national communication and formal education. It has been widely propagated by the late Neville Alexander (1936-2012) in South Africa and by many of his followers, including the present author. It is based on a robust set of insights gained from worldwide research on multilingual practices in which mother tongues and foreign languages are happily combined. (For a recent survey and language policy advocacy for Africa favouring multilingual models, cf. Ouane and Glanz 2010, 2011.)

Part of the new course for navigating African states through the troubled waters of language politics is the necessity to address some poorly understood facts and uninformed fears. Ignorance about sociolinguistic facts and subsequent 'fears of the unknown' (Obanya 1999a) have created some die-hard myths that feed into attitudes, which are again detrimental to sustainable modernisation and progress in Africa. These attitudes are shared by both African decision-makers and their international consultants. They are largely based on severe deficits regarding scientific knowledge about language matters, and remain informed by prejudice, stereotype and cliché, which do not stand the test of 21st century Applied African Sociolinguistics.

What are the relevant facts?

Fact 1: Territorial multilingualism is a natural feature of the human condition since it can be related to the latitudinal diversity gradient in biology (cf. section 2). More than that, it supports 
individual multilingualism, which is needed for inter-ethnic communication as a survival strategy for the benefit of numerically small ethnolinguistic communities which, as a matter of fact, constitute the vast majority of speech communities on our planet. Individual and institutional multilingualism, including translations (cf. Alexander 2005), are the most successful strategies to tap into available global knowledge for local benefits and avoid marginalisation.

Fact 2: Mainstream development discourse on Africa is infested with harmful Eurocentric perceptions. These are globally propagated and support neo-colonial hegemonic dominance, more recently in the guise of 20th and 21st century globalisation. There is no reason to assume that European models of statehood, which may have worked well in 18th and 19th century Europe, provide meaningful solutions to African problems of the late 20th and early 21st century. Institutional monolingualism based on explicit language policies is a more recent historical and localised development in human societies, particularly in Europe in the Modern Age. It reflects the political ideology behind the European 'Project Nation', which targets a nation state that is, ideally, widely homogenous in ethnic, cultural, and linguistic terms. Under the homogenising 'Project Nation', one particular language, and this is usually that of the ruling class/elite, is chosen to establish or maintain hegemonic dominance over others. In terms of policy, it leads to institutionalised official monolingualism, which is geared towards eventually replacing all other languages in order to approach the monistic ideological requirement of one state - one nation - one language. As far as colonial and post-colonial Africa is concerned, the most-applied strategy was to impose a 'neutral' or 'unifying' language, i.e. the language of the colonial master, with the hope implied that this would somehow automatically lead to the disappearance of Africa's received ethnolinguistic plurality and create truly Anglophone, Francophone, Lusophone, etc. countries that would add to the political muscle of the former colonial master in global political and economic matters. However, languages are, as a rule, never equal in terms of status within a given multilingual society: no language can be considered 'neutral' with regard to status, prestige, and power. If the political agenda is to establish hegemonic dominance of a particular language, the thing to do is to ideologically uplift it to superior status, thereby automatically degrading all other languages on the national territory to local vernaculars or dialects that are said to be unworthy, if not unequipped, to serve in higher domains of communication which, in turn, are reserved for the imposed language of power.

Fact 3: Conversely, all languages are equal in terms of communicative functions, in the sense that none is particularly equipped, or not equipped, to serve special communicative functions of a community, including their use in higher education in the 21st century. Any language will automatically adapt to any domain of use once it is regularly used in such domains. Note that all national and official languages of Europe underwent this process during the last few centuries when they challenged the hegemonic dominance of Latin, and to a certain extent French, and eventually replaced Latin and French even in the highest domains. In other words: African languages do not have to be 'developed' - they just have to be used in all domains, in particular in the most prestigious domains of 21st century philosophy, science and technology!

Fact 4: Attitudes towards languages, positive or negative, often have little or nothing to do with the languages per se, but rather reflect stereotype notions, cliché and prejudice of one speaker community towards other speaker communities in their vicinity. Language policies tend to be rooted in such ideological preconceptions that are not at all free of discriminatory, even racist, prejudice towards one's neighbours or immigrant populations. Therefore, it is politically dishonest and factually wrong to blame 'development' or 'underdevelopment' of economies 
and societies on prevailing patterns of language use, as the examples of the Asian so-called Dragon States show who run their business and emerging economies through their indigenous language(s). But: If one's fundamental ideological position is pro-European and anti-African, one will denounce African languages as 'primitive dialects' and glorify European standard languages as 'highways to sociocultural modernisation and economic development'.

In development discourse in Africa, as far as it is governed by Eurocentric ideology and based on little or no robust scientific sociolinguistic expertise, the above listed facts do not count. One reason is sheer ignorance of socio- and psycholinguistic facts on the part of most stakeholders. The other is the persistent prevalence of attitudes that are based on counter-factual assumptions, which will be discussed in terms of 'myths' (cf. also Obanya 1999b).

Myth 1: Territorial and institutional multilingualism threatens or blocks national unity and social coherence; therefore, and by implication, policies which would officially accept multilingualism are detrimental to socio-economic modernisation and development. This is a plain myth and based on monistic European nation state ideology, not a global fact that could be empirically supported by serious economic research. This myth is used for political propaganda in the post-colonies in order to: (a) discredit multilingual policies that would include indigenous languages; and (b) maintain the hegemonic dominance of the language of the former colonial master and, consequently, avoid jeopardising the quasi-natural privilege of the 'owners' of the language of power.

Myth 2: Individual multilingualism, particularly in early childhood, automatically means multiple 'semilingualism', i.e. multilingual speakers will learn and master none of the languages properly. Therefore, it is believed that multilingualism in terms of medium of instruction must have no place, at least no prominent place, in the educational system, which is geared towards the acquisition of advanced competencies in the exoglossic language of power. This myth is falsified by countless and world-wide empirical studies on language acquisition of multilingual individuals showing that full command of the mother tongue is beneficial to the learning of another tongue. On the other hand, speakers who have learned a language as 'additional' to their first and mother tongue language will, unless in very favourable environments, hardly ever be able to fully compete with native speakers of this language. Linguistic assimilation has its limits which, for instance in post-colonial African contexts, serves to maintain the privilege of the language owners who are the mother tongue-speakers of this language - like native speakers of English in South Africa.

Myth 3: Following from the previously mentioned myth, so-called home languages are assumed to negatively interfere with and, therefore, be detrimental to learning the official language which, as a rule, is a foreign language to most learners. This myth is particularly counter-productive since improving the command of the official language is what foremost everybody in Africa wants from education. On the contrary: Empirical studies clearly show that competent mastery of the mother tongue provides a solid basis for second and foreign language acquisition, in particular when the additional language is acquired during formal education.

Myth 4: Some languages, in particular those of the former European colonial powers, are essentially superior, most languages and in particular indigenous ones in the former colonial territories, are essentially inferior. This is also assumed for the indigenous/local cultures. Indigenous peoples, therefore, remain 'inferior’ as long as they do not assimilate, linguistically 
and culturally, to the representatives of the hegemonic (i.e. former colonial) power. This myth is based on Social Darwinist ideology. However, it remains attractive to people whose hidden agenda is to transform indigenous peoples into second-class copycats, who would not threaten the privileges of the language owners, because: who wants a copy when one can have the original? This myth is akin to and perpetuates apartheid ideology.

Myth 5 follows from this: Languages mirror developmental stages in a Social Darwinist model. People speaking superior languages are, by implication, themselves superior to people speaking inferior languages, so are their respective cultures or civilisations. This myth, of course, is born out of straightforward racism; it is implicit in all ideological combat wishing to establish and maintain European supremacy over non-European peoples, their cultures, and their languages (cf. section 3).

\subsection{The perils of Scylla and Charybdis in African language politics}

Under the impact of Eurocentric and Orientalist ideology, African language planners and policy-makers see themselves confronted with the need to take a crystal clear 'either - or' decision, either pro-African languages and contra-European languages, or pro-European languages and contra-African languages. However, this is a self-inflicted false dilemma (cf. Obanya 1999a), which has no empirical basis in sociolinguistic research but reflects imposed ideology. Forced into this fallacy, most African decision-makers opt for a choice of language policy pro-European language, which we have associated with the monster imagery of Scylla. This Scylla, in the guise of the prestigious European ex-colonial languages, will pick and devour with each of its several heads one African language after the other, like it did with the sailors of Odysseus' crew as described by the ancient Greek poet Homer. Each head of the monster would represent one ex-colonial language of European provenance (incl. Afrikaans), but also include Arabic in the northern and north-eastern parts of Africa. The result would eventually be massive language death in favour of shifting to the imported language and establish its use in a largely monolingual sociocultural environment. Scylla also works on a global scale: Quite a few opinion leaders of the world have assimilated to the idea that one global language for all would enhance peace and prosperity on this planet. They assume this global language to be some kind of non-native 'World English'. They overlook two things: (1) For many generations to come, inequality will prevail between native speakers of English and the majority of World English speakers, who will have to make do with non-competitive reduced local varieties - this amounts to global linguistic apartheid. (2) The proponents of a unifying world language cannot even be sure whether their favourite candidate, namely English, will not have been replaced by, for instance, Mandarin Chinese as new global lingua franca already by the end of the 21st century. As an aside: Those who advocate English as global and exclusive language for all are usually very good speakers of English already; their privilege, however, would be easily shattered with the rise of, for instance, Mandarin Chinese, or any other language. So, sailing by the Scylla monster may be an attractive solution at first glance, but could prove not to be attractive in the long run.

Opposite Scylla waits Charybdis. This is the idea of designing and implementing policies that subscribe to the acceptance of ethnolinguistic plurality and diversity. Sailing the political ship into the linguistic whirlpool would, however, have obvious advantages. A first gain would be philosophical: language policy would reflect the reality of the latitudinal diversity gradient in both biology and ethnolinguistic diversity, so politics would be 'one with nature'. The second 
gain would be ideological, namely the implementation of the romantic goal of Universal Linguistic Human Rights; this would be very much in keeping with another romantic goal, namely that of fostering 'authenticity' in terms of African personality and identity. The idea of universal ethnolinguistic diversity easily combines with the humanistic notion that, ideally, every speech community should enjoy the right to use its own first or home language for all purposes and in all domains of life, public and private. Politically and philosophically, and based on a wide notion of Human Rights, this idea would feed into ethnolinguistically informed strategies of power sharing through strong constitutional provisions for federalisation or by the strengthening of regional bodies: provinces or states within federations would be free to choose their working languages according to the local or regional profiles. The political gain would be inclusion of the 'masses' of the populace rather than their exclusion from participating in national politics. The socio-economic gain would be the democratisation of access to national resources, including immaterial resources in terms of exploiting the intercultural potentials of both cultural and linguistic resourcefulness. This approach reflects the new paradigm in sociolinguistics that views languages as resources on the same level as crude oil, gas, diamonds, gold, etc. (cf. Chumbow 1987: 22). And the more resources you have, the better. However, resources must be guarded, developed and carefully employed: they need investment before they can be exploited. This applies also to the language resources of any African country, they deserve to be harnessed by appropriate language policies and politics. Why should the basic idea behind this line of argument be harmful for African post-colonies?

Coming back to the monster imagery of Charybdis as a political strategy ('indigenisation') that would mirror African ethnolinguistic plurality. As a political option, it has two faces. As attractive as it may appear from the perspective just sketched out, as ugly it is from the perspective of running a modern state with multi-party representative parliamentary democracy working towards national cohesion, majority rule and minority rights, linguistic and cultural autonomy, but also world trade and global economics, and transnational security issues. While its attractive face may be called 'implementation of universal linguistic rights', its ugly face is called 'latent tribalism and anarchy'. As the sociocultural, religious, and political realities in Africa and beyond show, increasingly so in post-colonial periods (as witnessed by developments after the fall of the USSR, in the Middle East, and in Africa), this 'political monster' may hijack ethnolinguistic, cultural and religious identities and turn diversity into sources of terrorism and civil war, mainly for the simple purpose of gaining power and monopolistic control over national resources. It tends to leave behind the ruins of so-called 'failed states'. Charybdis' footmen in Africa, so to speak, are known under the names of The Lord's Resistance Army in Uganda, Boko Haram in Nigeria, Al Shabab in Somalia, Union des Patriotes Congolais in the Dem. Rep. Congo, Sudan People's Liberation Army and Sudan People's Liberation Movement in South Sudan, and others. One of the characteristic features of these militant groups is that they may have started off guided by idealistic goals such as rightful liberation from political, economic, religious or racial oppression, but soon have transgressed the very thin line between their original goals and plain criminal terrorism. Looking at a global map of so-called failed states, we are struck by the parallel distribution if compared to biological and ethnolinguistic diversity in terms of the latitudinal diversity gradient (cf. section 2). Therefore, one wonders whether or how such 'failed states' link up with 'wrong' language policies that feed into underperforming educational systems which, in turn, lead to social pathology in the affected African regions. 
To conclude this section with a question: Is it Africa's only choice, with regard to language policy options, to either become a copycat second-class member of the First World when the state vessel sails too close to Scylla, or to remain eternal beggar from the Third World when the ship runs too close to Charybdis? Or, is there a way out of this dilemma situation and, proverbially speaking, can Africa have her cake and eat it too? The following section will provide an optimistic answer.

\section{Overcoming the African language policy dilemma}

Until this day, African policy-makers and policy-implementers resemble Odysseus who faces the challenge of navigating his ship through the Strait of Messina between Scylla and Charybdis. Like Odysseus, they only see 'either - or' options: either take the risk of losing part of their crew when passing Scylla, or losing the whole ship by running it into the whirlpools of Charybdis. In terms of language policy decisions: Opting to pass by Charybdis would mean to largely indigenise the whole educational system by using African home languages and lingua francas from pre-school nurseries through primary, secondary, and tertiary educational cycles, and to re-direct English (or French or Portuguese) to the status of a foreign language, which need not be introduced, as a subject, before the secondary cycle. African politicians and educational practitioners follow Odysseus and avoid this option, fearing to sink the whole ship of the national education system in the whirlpools of too many and purportedly inadequate African mother tongue languages - with no expected survivors. Interestingly, however, this is exactly the course that the so-called developed First World countries and emerging economies steer: They maintain endoglossic monolingual mother tongue education throughout all educational cycles, with exoglossic so-called world languages being introduced as subjects of teaching and learning not before the secondary cycle of education.

As a matter of fact, and taking the Charybdis imagery to its end, this reflects the true naval challenges of the Messina Strait: A whirlpool does exist there, caused by strong adverse currents, but it is seldom dangerous. ${ }^{10}$ Charybdis remains a myth, both as a sea hazard and as a negative option for language policy in Africa.

Like Odysseus and in order to avoid Charybdis, most African decision-makers and educational practitioners opt for Scylla, knowing and facing the risk of losing considerable parts of the crew. In the educational system, this means that running formal education almost exclusively through the ex-colonial and foreign languages will leave masses of drop-outs and class-repeaters behind, unless passing exams becomes a formality without really reflecting successful learning efforts, which would make formal education a farce. To remain in the imagery: The remaining crew members on the ship survive, i.e. the learners in formal education, but they come out of the strait as they have entered it - having learnt little or nothing, other than merely surviving in the system.

In terms of language policy options for Africa, the right thing to do is to, indeed, avoid risky 'either - or' options in view of available 'as well as' options. The policy is known under the label mother tongue-based multilingualism, i.e. using both the mother tongue as well as other languages as subjects of instruction, most of all. Optimal implementation of mother tongue-based multilingualism in formal education requires embedding in so-called additive no-exit models

\footnotetext{
${ }^{10}$ Retrospectively and with our geographical and naval knowledge of today, Odysseus made the wrong choice, sacrificing members of the crew for nothing. He could have sailed smoothly in the middle of the strait, in safe distance from Scylla, because the Charybdis risks turn out to be totally overestimated.
} 
(cf. Ouane and Glanz 2010, 2011). The idea behind this is to maintain home languages and/or African lingua francas throughout the system (= additive no-exit model), and to introduce additional (African and non-African) languages as subjects. The medium of instruction remains the mother tongue/home language or a lingua franca, which is already mastered by the learners, rather than using a non-African language to replace the former as medium of instruction. Studies in Africa and on a world-wide scale show the benefits of systems that are based on continuing mother tongue medium of instruction, including the effect of better learning of foreign languages. Studies show that there is a direct correlation between subject scores and proficiency in the language in which the subject is taught. In order to promote good subject scores and throughput of students, therefore, mother tongue medium of instruction would be first choice. It would allow for efficient foreign language acquisition via subject of instruction rather than using poorly mastered foreign languages as medium of instruction, in particular for content matter other than foreign language learning itself.

As a matter of fact, practicing multilingualism outside the classroom is an almost ubiquitous and growing feature of African children and teens, this capacity can be profitably used also in the classroom. Further, empowerment of home languages and African lingua franca through use in higher and prestigious domains of education, more recently referred to as intellectualisation of languages (cf. Sibayan 1999, quoted in Alexander 2005), enhances the self-esteem of their speakers and fosters uninhibited development of African identity and personality. It also enhances individual deep learning and cognitive development through tapping into the mother tongue-based multilingual competencies of students. For the educational system to produce African personalities of some intellectual and academic standing and have an open mind and access to the world, one should take note of Mahatma Gandhi's idea of his house, who is quoted to have said:

I do not want my house to be walled in on all sides and my windows to be stuffed. I want the cultures of all the lands to be blown about my house as freely as possible. But I refuse to be blown off my feet by any.

Why should educational systems not be built like Ghandi's house with many windows facing all directions? In this imagery, the windows are the languages of origin of thought and wisdom, local and foreign. In Africa, with both African and non-African cultures freely blowing about the house, the landlord should be well equipped to face the challenges of the 'Earth Summit Agenda 21', namely Think globally, act locally. This works well as long as one has a firm stand in one's own culture not to be blown off one's feet by a foreign culture or the shock waves of neo-colonial globalisation. To think globally and act locally: one would have to use local languages in order for the so-called masses of the people to actively participate in nation building, sociocultural transformation and economic development. If one wants or needs to talk about such activities globally: One can use foreign languages like English, French, etc. as International Languages of Wider Communication, which would be professionally taught as subject matter at school. At the same time, one would find oneself on the king's road to 'Decolonising the mind' (Ngugi wa Thing'o 1986), meaning riddance of post-colonial hegemonic linguistic dominance, with global and local languages on equal footing. Would that be asking too much of language politics in Africa and of a truly African educational system? 


\section{References}

Alexander, N. 2005. The potential role of translation as social practice for the intellectualization of African languages. (Keynote address delivered at the XVII. World Congress of the International Federation of Translators, held at Tampere, Finland, 4-7 August 2005; unpubl.)

Chumbow, B.S. 1987. Towards a language planning model for Africa. Journal of West African Languages XVII.1: 15-22.

Ehlich, K. 2009. Sprachenpolitik in Europa - Tatsachen und Perspektiven. In C. Anthonissen and C. von Maltzan (Eds.) Multilingualism and language policies in Africa-Mehrsprachigkeit und Sprachenpolitik in Afrika. Stellenbosch Papers in Linguistics PLUS 38: 26-41.

Ferguson, C.A. 1959. Diglossia. Word 15: 325-340.

Fishman, J.A. 1967. Bilingualism with and without Diglossia; Diglossia with and without Bilingualism. Journal of Social Issues 23(2): 1-143.

Hibbert, L. and C. van der Walt (Eds.) 2014. Multilingual Universities in South Africa. Reflecting Society in Higher Education. Bristol-Buffalo-Toronto: Multilingual Matters.

Kaschula, R. 2013. Challenging the Forked Tongue of Multilingualism: Scholarship in African Languages at South African Universities. In C. Altmayer and H.E. Wolff (Eds.) Africa: Challenges of Multilingualism. Afrika: Herausforderungen der Mehrsprachigkeit. Les défis du plurilinguisme en Afrique. (SPRACHe-Kultur-Gesellschaft 14.) Frankfurt a. M.: Peter Lang. pp. 203-221.

Lewis, M. et al. (Eds.) 2015. Ethnologue: Languages of the World, Eighteenth edition. Dallas, Texas: SIL International. Available online: http://www.ethnologue.com (Accessed August 2015).

Ngugi wa Thiong'o. 1986. Decolonizing the Mind. The Politics of Language in African Literature. Nairobi: East African Educational Publishers Ltd.

Obanya, P. 1999a. The Dilemma of Education in Africa. Dakar: UNESCO Regional Office.

Obanya, P. 1999b. Popular Fallacies on the Use of African Languages in Education. Social Dynamics (Special Issue: Language and Development in Africa) 25(1): 81-100.

Ogone, J.O. 2013. Devolution and it Implications to the Indigenous Languages of Kenya. In C. Altmayer and H.E. Wolff (Eds.) Africa: Challenges of Multilingualism. Afrika: Herausforderungen der Mehrsprachigkeit. Les défis du plurilinguisme en Afrique. (SPRACHEKultuR-Gesellschaft 14.) Frankfurt a. M.: Peter Lang. pp. 145-156.

Ouane, A. and C. Glanz (Eds). 2011. Optimizing Learning, Education and Publishing in Africa: The Language Factor. A Review and Analysis of Theory and Practice in MotherTongue and Bilingual Education in sub-Saharan Africa. Hamburg-Tunis: UNESCO Institute for Lifelong Learning (UIL), Association for the Development of Education in Africa (ADEA). 
Ouane, A. and C. Glanz. 2010. Why and how African should invest in African languages and multilingual education. An evidence- and practice-based policy advocacy brief. Hamburg: UNESCO Institute for Lifelong Learning (UIL).

Ruíz, R. 1984. Orientations in Language Planning. NABE Journal 8(2): 15-34.

Said, E. 1978. Orientalism. New York: Pantheon.

Wolff, H.E. 2013a. On Visibility and Legitimization of Languages: The 'linguistic landscape' in Adama, Ethiopia. Aethiopica 16: 149-191. (In cooperation with Sileshi Berhanu and Getinet Fulea.)

Wolff, H.E. 2013b. Was ist eigentlich Afrikanistik? Eine kleine Einführung in die Welt der afrikanischen Sprachen, ihre Rolle in Kultur und Gesellschaft, und ihre Literaturen. (SPRACHE-Kultur-GeSEllschaft 13.) Frankfurt a.M.: Peter Lang. (In cooperation with Ari Awagana and Marion Feuerstein.)

Wolff, H.E. 2014a. Sprache als Schlüssel - Sprache als Ressource. Eine Positionsbestimmung der deutschsprachigen Afrikanistik. In Afrikanische Deutschland-Studien und deutsche Afrikanistik, ed. by M. Espagne, P. Rabault-Feuerhahn, D. Simo, 19-48. (Saarbrücker Beiträge zur Vergleichenden Literatur- und Kulturwissenschaft, Vol. 72.) Würzburg: Königshausen und Neumann.

Wolff, H.E. 2014b. Navigating multilingualism between Scylla and Charybdis. Facts and fears, myths and attitudes: the politics of language in Africa. Presented at the Rhodes University Colloquium on Multilingualism, September 22, 2014 (unpubl.).

Wolff, H.E. 2015. Sprachen und nationale Minderheiten in Afrika. Kann Europa daraus etwas lernen? Papers from the 9th International Ferdinand Tönnies Symposium, Husum, 13-14 November 2015, ed. by Thomas Steensen (forthcoming).

Wolff, H.E. 2016a. Language and Development in Africa. Perceptions, Ideologies and Challenges. Cambridge: Cambridge University Press.

Wolff, H.E. 2016b. Socio- and applied linguistics. In The Languages and Linguistics of Africa: A Comprehensive Guide, ed. by T. Güldemann. Berlin: de Gruyter Mouton (in press). 